
\title{
28 Research Suare \\ Self-Reported Accounts of Assisted Reproductive Technology Treatments: The Voice of Ghanaian Women
}

Kwadwo Asante-Afari ( akwadw02003@yahoo.com )

Ghana Health Service

Eugene KM Darteh

University of Cape Coast

David Teye Doku

University of Cape Coast

\section{Research Article}

Keywords: Assisted reproductive technology, treatment, experiences, women

Posted Date: June 14th, 2021

DOI: https://doi.org/10.21203/rs.3.rs-567449/v1

License: (c) This work is licensed under a Creative Commons Attribution 4.0 International License.

Read Full License 


\section{Abstract}

Background: In Ghana, the infertility prevalence rate continues to be high. To avert this phenomenon, individuals with fertility challenges access assisted reproductive technology (ART). This paper explores the experiences of women who have undergone ART treatments.

Methods: Using a qualitative research design, the paper explores the self-reported account of 35 women who have gone through assisted reproductive technology procedures and awaiting to be tested for pregnancy. A semi-structured interview guide was utilised to explore women's experiences. The thematic analysis approach was used to analyse the data.

Results: Findings from the study indicated that some women sought ART treatment to save their marriages from collapse while others indicated that pressure and demands from in-laws and families, as well as shame, forced them to utilise ART. Women who went through ART treatment services complained of the high cost of the treatment. As a result, some borrowed money from friends, family members, banks and in some instances sold their assets to pay for their treatments. Self-reported health implications such as anxiety, depression and changes in menstrual flows were reported by some women who went through the procedure. Other experiences such as sleeplessness, weight loss, joint pains, whole body pains, breast tenderness and bleeding were also reported. Women who went through the procedure also reported disruption in sexual life and daily routines activities.

Conclusion: Undergoing ART treatment for infertility comes with experiences such as hospitalisation, disruption of work and daily activities, high cost, health and other implications. There is the need for patients to go through thorough counselling especially about the entire procedure and perceived implications associated with assisted reproductive technology treatments.

\section{Introduction}

Infertility is a major challenge among couples, especially in developing countries. Globally, it is estimated that about $15 \%$ of women in their childbearing age are affected by infertility and the prevalence is expected to increase to 7.7 million by 2025 despite the available treatments such as Assisted Reproductive Technologies (ART) (1). Sub-Saharan Africa is one of the regions with the highest infertility prevalence (1). However, countries differ in the prevalence rate. For example, Gambia has an estimated 9 percent infertility rate, 21.2 percent in North-Western Ethiopia (2) and between 20 percent and 30 percent in Nigeria (3). In Ghana, the infertility prevalence rate is 11.8 percent among women and 15 percent among men (4).

Traditionally, the main causes of infertility have been ascribed to witchcraft, co-wives, envious neighbours, in-laws and past lovers (5). Voodoo, curses by ancestors or deities, evil spirits are recognised as the other traditional causes of infertility (6). Scientifically, infertility may be the results of genetic abnormalities, infections and sexual behaviour among others. Infertility among women is commonly caused by lack of ovulation, sexually transmitted infections, fibroids, sickle cell disease $(7 ; 8)$ whiles in 
males, low sperm count and semen quality have been identified as the commonest causes of infertility (9).

Previous studies have argued that infertile women face social stigmatisation, economic hardships, social segregation and violence or expelled from marital homes $(10 ; 11)$. In some Ghanaian societies, infertile women could be subjected to physical and emotional abuse (12). These practices depict that the Ghanaian society is against childlessness hence, their adverse treatments and attitudes towards people with fertility problems.

To avoid the challenges associated with infertility in Traditional African society, women explored various ways to achieve parenthood in the past. For example, a wife's engagement in extramarital relations to have a child due to the infertility situation of the husband was overlooked (13). In the same way, a cleansing ritual was held to sanction a child born out of wedlock by a wife to an infertile husband (14). A similar tradition persisted among the Lo Dagaa tribe in Northern Ghana where a man becomes the legal father to all children born to a woman as long as he has paid the bride wealth (15).

In some other cultures, an infertile couple has the opportunity to bring up children as their own even though such children may not be related to them biologically. For example, a younger sister or a relative of an infertile wife may be brought into the marriage to bear children for the infertile couple (16). Another means adopted by infertile women to solve their infertility challenge in the Traditional African society was to marry or engage other women and claim ownership of all her offspring (17). This kind of relationship existed in different forms. For instance, a woman who has given birth to males could marry another woman to bear female children for her and vice versa.

Re-marriage and/or divorce are considered as other possible means of solving infertility challenges (18). Others also relied on adoption as an alternative way of coping with infertility although it was less accepted in the developing world (19). The use of herbal and/or complementary and alternative medicines (CAM) to treat infertility or enhance fertility was also practised (20)

Additionally, waxing and waning of the moon were believed to influence a woman's fertility. Based on this notion, traditional astrologists were consulted for the provision of the rightful days in the month for sexual intercourse that would result in pregnancy (21). From the discussions, it appears that equal reproductive roles of both men and women in achieving pregnancy were not recognised in the past. Reproduction was thought to be the sole role and responsibility of the woman. Due to this reason, fertility rituals and traditions mostly targeted females.

However, in present times, the notion of reproduction has changed. Scientists have ascertained that reproduction required the male sperm and female oocyte. As a result, infertility is medically addressed as a couple's issue rather than blaming it on the woman.

For many couples who are faced with infertility, conventional medical therapies, including various Assisted Reproductive Technologies (ART) are explored. Assisted Reproductive Technology is defined as 
"all treatments or procedures that include in vitro handling of both human oocytes and sperm, or embryos, to establish a pregnancy. These include, but not limited to, in vitro fertilization and embryo transfer, gamete intra-fallopian transfer, zygote intra-fallopian transfer, tubal embryo transfer, gamete and embryo cryopreservation, oocyte and embryo donation, and gestational surrogacy. ART does not include assisted insemination (artificial insemination) using sperm from either a woman's partner or a sperm donor" (22). Since 1978, ART has provided an alternative solution for many couples that are faced with fertility problems (23). By 2010, 55 percent of countries in the world were offering In-Vitro Fertilisation (IVF) services (24).

In Ghana, the first fertility hospital was established in 1995 and by 2017, the total number of fertility hospitals has increased to 12 (25). The recent upsurge in the number of fertility hospitals in Ghana probably suggests that despite the physical, social and financial challenges of accessing ART, the services are desirable due to the premium put on children in the country (26). However, scientific studies about this topical area in Ghana is limited. As a result, this study seeks to explore the self-reported experiences of undergoing ART treatment in Ghana. Assessing the experiences of women who seek ART treatment is useful since it tends to inform service providers to better understand clients' needs, expectations and challenges. It may also provide firm grounds for improvement in the areas of provision and utilisation of ART in Ghana.

\section{Theoretical underpinnings}

The behavioural model of health services utilisation (27), which was revised by (28) underpins this study. The import of the framework is that an individual's decision to seek infertility treatment depended on three interrelated factors: (a) predisposing factors (i.e. age, gender, socioeconomic status, health beliefs); (b) enabling factors (insurance, income status, access to medical care, and other individuals, family, and community resources) and (c) perceived and evaluated need (such as perception of a problem or an existing health condition). The model opines that an individual's ability to utilise fertility treatment is based on a personal decision that is influenced by his/her role in society as well as the existence of the needed services at a particular time.

The predisposing factors are grounded on the fact that the tendency for an individual or a family to use health services can emanate from a set of personal characteristics. Individual predisposing characteristics are grouped into three distinct collections. These are demographic characteristics (age, marital status, religion and sex), social conditions and perceptual influence in terms of belief (27). These sets of variables come together to determine the social status of the individual in the society, lifestyle, physical and social environments and the use of health services. In the utilisation of ART, an individual's predisposing factors may play a significant role to utilise service but there must be enabling characteristics such as financial resources to enhance utilisation. The financial resource includes an individual's income, wealth and health insurance status. 
On the other hand, institutional factors which consider service availability, organisation and delivery of services, workforces and accessibility also come to play in the treatment of infertility. In most cases, when these factors are favourable, individuals with infertility tend to utilise ART services more and vice versa.

The final factor which was considered by the model was the need factors. At the individual level, (29) distinguished between the perceived need for health services (i.e., how people perceive and experience their general health, functional state and the symptoms the condition presents) and evaluated need (i.e., professional assessments and objective measurements of patients' health status and need for medical care). All things being equal, after self and medical assessments have proven the need for ART treatment, infertile women are likely to seek treatment.

The model was modified to include three mutually related characteristics: health care system, use of health services and consumer satisfaction (30). Further, the updated model also predicted that consumer satisfaction comes to play and this particular factor had the potential to motivate health care users in making a choice whenever they are confronted with a health problem. In summary, the model established that the characteristics of users and that of health service providers have a direct correlation with the utilisation of ART treatment.

\section{Data And Methods Study setting}

This study was conducted in five Fertility Hospitals in Ghana. Three of these hospitals are located in Greater Accra, the capital city of Ghana and the other two facilities are located in Kumasi, the secondlargest city in Ghana. Accra has an urban population of 2.27 million while Kumasi the second largest city has about 1,468,609 inhabitants. These facilities were purposively selected for the study mainly because they are among the first fertility clinics and hospitals to be established in the country. A qualitative research design using semi-structured interviews was adopted to explore the self-reported experiences of women undergoing ART procedures in Ghana. The interview was structured into thematic areas including

\section{Study population and sampling}

The population of 35 self-cycled women (women who used their own oocyte/egg for the ART treatment procedure) who had gone through ART treatment processes and are waiting to be tested for pregnancy was purposively for the study. Respondents were recruited for the study after personal had been made to ascertain their participation in the study

\section{Data collection}

An interview guide was used to solicit information about women's experiences after going through the treatment. The interview guide was categorised into themes of inquiry which included the socio- 
demographic profile, treatment trajectory, decision, cost, information and counselling, health risks, sociocultural influences and perception about the use of ART. Respondents were interviewed in the English language and Twi (a Ghanaian dialect). The back-translation method was used to translate the interviews conducted in Twi into the English language for analysis.

Before the start of the interviews, information about the study, the use of the data being collected, and an estimated time frame of the interview were made known to the participants. Confidentiality of respondents and their information were maintained throughout the study by conducting the interviews at the convenience of respondents and also keeping data out of the public. Prior consent was sought from participants for audio documentation of the interview. Upon agreement, participants signed informed consent.

\section{Data analysis}

Interviews conducted in the local dialects were accurately translated and transcribed into the English language. Gaps identified during this process were filled by referring to field notebooks and interview tapes whenever there was a need. Data from the interviews were analysed thematically.

\section{Ethical considerations}

Ethical approval was obtained from the University of Cape Coast Institutional Review Board with approval number UCC/IRB/A/2016/54. Approval was also sought from the Ghana Health Service Ethics Review Committee (approval number GHS-ERC:02/10/2016).

\section{Results}

\section{Socio-demographic characteristics of respondents}

The background characteristics of respondents indicate that half (18) out of the total respondents (35) were aged 30-39 years, while 10 of the respondents were between ages $40-49$ years. Respondents who had completed tertiary education constituted the majority (20) compared to only 2 respondents each of whom had no formal education and primary education. Most of the respondents (30) were in marital relationships whiles 5 were not married. Also, the majority (28) of respondents were Christians and 7 were Moslems.

\section{Reasons for seeking ART intervention}

Individuals' decision to seek medical intervention for infertility condition is influenced by several factors. From the interviews, it emerged that pain, shame, pressure from spouse and delays in getting children after long years of marriage were a major driving force.

A respondent who went through pains and shame and at a point decided to take her life narrated her experience: 
'Insults, pain and shame from my friends, family, and neighbours forced me to utilise ART'.

(43-year-old woman)

Another respondent who did not have a child after 22 years of marriage had this to say:

'After 22 years of marriage, we have not seen anything. I have been accused of using my children for money rituals. I think seeking ART services may help'.

(45-year-old woman).

\section{Source of information on ART availability and preferred facility}

Access to, and source of information help users to know the kinds of services available, decide whether to seek ART treatment and which facility to seek treatment from. Data gathered from this study revealed that respondents got to know about ART from family and friends, the internet, electronic media (TV and radio), and from school. A 45year old respondent who had information on ART treatment from a family friend said:

'My husband's friend spoke to us about the use of ART. It was after the discussion that we got to know that his twins were born through the use of ART. We became encouraged and quickly went to the facility he had his children for inquiries'

(45-year-old woman)

Another 33-year old respondent who had information on the internet had this to say:

'My husband and I read about ART on the internet and later went to the hospital to ask further questions'.

(33-year-old woman)

A health worker who heard about ART in school said:

I heard about ART through my education at the nursing school but I did not believe it was done in Ghana until I watched a health programme on a television

(36-year-old woman)

\section{Cost of ART services}

Cost and affordability of ART procedure are considered the key variables that affect an individual's or couple's utilisation. The majority of the woman (20) complained about the high cost of going through ART treatment. For example, a 34year old respondent recounted how much she paid for the procedure: 
I paid $\$ 3,550$ (Ghc 15,750.00) for my treatment. I never expected that the cost would be so high but I had to find money and pay because I wanted to save my marriage.

(34-year-old woman)

Another respondent had this to say about how much she paid for the ART treatment:

'The cost of my treatment was $\$ 4500$ (GHC 20,250.00). The cost is on the higher side but if you think of what you need; that may be more valuable than the money.'

(37-year-old woman).

A respondent who did not border about the cost of treatment provided the procedure was successful had this to say:

I spent about $\$ 9000(G h c 40,500)$ so far. Although it is very high, I don't care about the cost. I am ready to invest all my money and wealth to have a baby'

(49-year-old woman)

\section{Sources of securing funds for ART treatment}

The cost of accessing ART was a challenge to many seeking the service. Particularly, respondents sourced money from parents, friends and loans from the bank or sold their property to pay for their ART treatments. A respondent who sourced money from parents, friend and through her savings before she was able to access the treatment narrated that:

I sourced money from my parents, friends and through my savings. My husband told me he has no fertility challenge and so he did not pay a pesewa

(36-year-old woman)

Another respondent who was supported by her mother in addition to the money she raised from the selling of their property narrated that:

My mother supported me with half of the cost and the rest was paid by my husband and I after we sold our property

(40-year-old woman).

A respondent who took a bank loan to have the ART treatment done had this to say:

'I took a loan from the bank for me to go through this treatment. I am a civil servant and it is going to take me years to pay back this loan'.

(48-year-old woman). 


\section{Counselling}

Counselling is an integral part of the ART services and processes. The counselling session offers clients the opportunity to ask questions about the procedure. Women shared aspects of the counselling procedure and how satisfied they were. A client who received counselling and was satisfied had this to say:

A respondent who was taken through the counselling processes and was also satisfied recounted how the counselling took away her fears:

'I was taken through counselling on the whole ART procedure. It included the drugs, retrieval of gamete and preservation of excess gametes and embryo. This took away my fears'.

(37-year-old woman).

A 34year old client who could only remember the counselling on cost and payment mentioned that:

I only remember that I was counselled on the amount of money I will pay for the process and the fact that it was not refundable. I did not listen to the rest of the counselling even though I was in the counselling room'.

(34-year-old woman).

\section{Consent}

After clients had gone through the counselling processes, they needed to sign the consent form to affirm their willingness to comply with the conditions to go through the procedure. A respondent who was not interested in the content of the consent form but just appended her signature explained that:

'I was given a consent form to sign but I did not read at all. All that I looked for was where to sign. I was very much frustrated and wanted the process done'.

(36-year-old woman)

A 40-year-old woman who could not read and write but was handed a consent form said:

'We were given some form to sign after the counselling processes. I cannot read and so my husband signed the form. I do not remember the exact things the document contained'.

(40-year-old woman)

Other respondents did not sign any consent form because they were not given by service providers. A respondent who did not sign any consent form before going through the processes said: 
I was not given any consent form to sign and I was also not aware of it... I think they might have forgotten about it

(36-year-old woman)

\section{Self-reported health and other implications of ART on users}

The use of ART has resulted in the treatment of millions of infertility cases. Nevertheless; the use of the technology has been perceived to have resulted in varied health challenges especially to women. A respondent who experienced abdominal and joint pains any time she took prescribed medication narrated her experience:

I started experiencing abdominal and joint pains anytime I took my medications

(34-year-old woman).

Apart from the medical implications, there were also some socio-economic implications for using ART treatment. A respondent who was found working even on the hospital bed said:

'Do you see my laptop? I am busily working because this is a busy season at work. I may lose my job if I don't do this'.

(33-year-old woman)

Another client who had to prepare the timesheet for her employees had this to say:

'The treatment has affected my work. I am an accountant and as the month is getting to an end, I have to prepare the timesheets and salaries of the staff'.

(37-year-old woman).

Other respondents who took their annual leave or permission from work did not have to force themselves to work when they were at the hospital. For instance, a respondent who purposely took her annual leave for her to go through the treatment confirmed that:

I took my annual leave before I started the procedure. The treatment has not affected me in any way because I have handed over properly to my next in command

(36-year-old woman)

Other respondents reported that they were psychologically disturbed. For example, a client who was psychologically disturbed as she was thinking about her pregnancy test result shared her anxiety:

'The anxiety to know the result of the whole procedure was too much for me. I wished the pregnancy test was done as soon as possible'. 
(35-year-old woman)

Further, respondents complained that their sexual life has changed as a result of going through ART treatment. A 40-year-old respondent whose sexual life changed as a result of the treatment share her experience:

'My sexual life has changed ever since I started this treatment. I have been asked to do away with sex until the pregnancy test is done'.

(40-year-old woman)

\section{Discussion}

Results from the study indicated several reasons for the usage of ART to fulfil parenthood desires. For example, some women indicated that they were embarrassed by their inability to have children after a long period of being in marital relationships. Others attributed their usage of ART to grief as a result of their inability to have children whilst other did so to avoid insults, pain and shame from my friends, family, and neighbours. This suggests that parenthood is a lifetime goal that must be fulfilled in Ghanaian society. It also appears that the extended family system that perceives that the family grows when individuals in the family begin to procreate force women to seek treatment for their infertility. Further, the belief that the purpose of marriage was not complete until couples procreate could also serve as a source of motivation for married women who have fertility challenges to seek treatment (31). Pressure and abuses from spouses, friends and in-laws were also observed to have influenced the decision to seek ART treatment. These findings corroborate the ten decision points in the Help-Seeking Theory by (32). These decision points predict how individuals who are affected by conditions such as infertility could be influenced to make treatment decisions.

Furthermore, the behavioural model by (28) supports the decisions on why women sought ART treatment. The import of the model to this study is that an individual's decision to seek treatment including infertility depends on three interrelated factors: (a) predisposing factors (i.e. age, gender, marital status, socioeconomic status, health beliefs); (b) enabling factors (insurance, income level, access to medical care, individual, family, and community resources) and (c) perceived and evaluated need (such as the perception of a problem or an existing health condition). The implication of this model to the study is that an individual's ability to utilise ART services may be based on couples' decisions which are influenced by their role in society as well as the existence of expertise and other needed services at a particular point in time. It must also be noted that all things being equal, couples who are faced with fertility challenges may consider the availability, accessibility, accommodation, affordability and acceptability of the procedure before utilisation.

The Source of information about the availability of ART to clients played a very important role in the decision to use ART services. In Ghana, sources of information about the availability of ART services include the electronic (internet, TV, and radio), print (magazines and newspapers) and, most importantly 
satisfied clients, friends and members of social networks. Most women based their decisions to use a particular ART procedure and even a health facility on the testimonies of satisfied clients. This finding supports the Network-Episode Model (NEM) of health care utilisation which was developed by (33). The model describes the influence of the interaction between an individual who is faced with a health challenge and his social networks in seeking health care. These social groups could be the source of information about the treatment and may also provide emotional as well as financial support when the need arises. Also, utilisation of ART could be influenced by the decision of an individual's social relations which could be internal (family) or external influences (friends and other social groups).

Considering the economic aspect of the utilisation of ART in Ghana is worth discussing as it has influential effects on accessibility and utilisation of fertility treatment by prospective users. The study revealed that the cost of ART services in Ghana was high (\$3500 - \$9000) and varied among the various fertility hospitals. Cost among other things comprised of medical consultations, drugs, laboratory services, medical processes including retrieval of oocyte, fertilisation and transfer of embryos and other charges. The high cost may prevent couples who are faced with fertility challenges and have financial difficulty to abandon the desire to use the ART services. This is because they may not be able to afford the expenses of the procedure. (34) observed that the high cost of utilising ART services was the main impediment to a lot of couples who are faced with fertility conditions. Similarly, (35) acknowledged that the cost of accessing ART service potential to cause a limit to couples who have lower socioeconomic status. Other studies have also identified that the treatment cost in low-income countries including Ghana could cost more than half of an individual's yearly income (36;37). In Ghana where public financing and insurance support for ART services have not been part of health policies and legislative procedures, clients who utilise ART services do so from out-of-pocket.

As a result of the high cost of accessing ART treatment and services in Ghana, women who needed to go through ART treatment at all course borrowed money from friends, relatives, and banks or sold their assets to raise money to go through the procedure. The implication of this is that individuals who go through such ordeals may be very disappointed when they are not able to achieve pregnancy and delivery. Further, it also means that couples who are faced with infertility challenges and have limited financial resources may not be able to meet their parental desire.

Couples who start with ART treatment procedures in most situations have higher expectations of accomplishing positive results thereby meeting their parenthood desires. However, the uncertainty about treatment resulted in increased physical and psychological effects on couples. Studies have confirmed that women who go through unsuccessful cycles suffer the most due to the invasive and expensive treatments they go through $(38 ; 39)$. It has also been opined that stress accompanying infertility and its subsequent treatment may also have effects on prospective couples even when they become successful with the treatment procedures (40).

Results of the study established a correlation between couples who accessed ART procedure and reported anxiety and depressive symptoms. It appears that clients considered these symptoms as normal

Page 12/18 
which accompanied the use of ART treatments because they could not disclose these to the service providers. Others could not disclose these symptoms because complaints about the symptoms could probably lead to the postponement or cancellation of the procedure at a particular time.

Self-reported health and other implications of going through ART treatment were also identified by the study. Adversely, the jobs of women were affected due to the treatment schedules. Almost all civil and public servants who were involved in the study either took their annual leaves or took some days off to go through the treatment procedure. Others who were not able to take their leave periods were found working even when they were on their hospital beds. However, the hospital environment was not conducive as clients were not able to work to their satisfaction probably because they were thinking about the treatment procedure. This discussion clearly shows that the demands from work conflicted with the psychology and time needed for people who went through ART treatment. Support from the workplace and job flexibility would have been key to clients who went through ART treatment but these were absent probably because employees had concerns to inform their employers about their fertility conditions due to the societal perception about infertility and the use of ART.

Some women who went through ART treatment complained of experiences such as having lost weight, others gained weight, sleeplessness, joint pains, whole body pains, breast tenderness while others bled. Other women complained about disruptions in their sexual lives because they were restraint from having sexual intercourse until they are confirmed pregnant by a laboratory test. (41), observed that general medications and other hormone drugs used to treat infertility may result in psychological including sleeplessness or interruptions, mood swings, depression, mania, irritability, and other related challenges.

Assessing clients' experiences especially on infertility treatment has helped to better understand clients' challenges, needs and expectations. This will result in improvement in the delivery of quality care and services to clients. Despite the strength, data collection was confined to only five fertility clinics and hospitals out of about 12 in the country. Although an attempt was made to include all facilities, the very few facilities that accepted to be part of the study were used. The inclusion of all other fertility clinics and hospitals in the study would have probably generated an improved generalisability of the findings.

\section{Conclusion}

The study among other things identified that women's decision to use ART was influenced by physical, economic and psychological factors. Whiles in most cases, couples anticipate ART treatments to be successful, safe and free from any physical or emotional challenges, some women experienced disruption of work, daily routines, and medical complications, financial burden and in some cases geographical relocation for varying reasons. These adverse implications sometimes become impediments to achieving the gender and social roles of being parents.

Based on these reasons, patrons of ART require counselling on the procedure from professional counsellors who may be attached to the hospitals. The counselling processes must highlight the entire procedure of treatment and their implications, cost, success rate and how treatment may influence daily 
course life. Further, there is the need for the state to enact regulations on the use of ART as this helps to address concerns that may arise from the use of this relatively new medical technology in the country.

\section{Declarations}

\section{Acknowledgements}

The authors wish to acknowledge the support of all respondents who willingly shared their experiences on the use of ART.

\section{Authors' contributions}

KAA contributed to the study design, data collection and interpretation, and manuscript preparation; EKMD and DTD contributed to the study design, data interpretation and manuscript preparation. All authors read and approved the final manuscript

Funding: This research did not receive any specific grant from funding agencies in the public, commercial, or not-for-profit sectors.

\section{Availability of data and materials}

The datasets analysed in the current study are not publicly available due to their nature. The dataset used to support the findings of this study is contained within the article.

\section{Ethics approval and consent to participate}

Informed written consent was obtained from all participants, and this study was approved by the University of Cape Coast Institutional Review Board with approval number UCC/IRB/A/2016/54. Approval was also sought from the Ghana Health Service Ethics Review Committee (approval number GHSERC:02/10/2016). The study was carried out following the ethical guidelines of the University of Cape Coast, Ghana.

Consent for publication: Not applicable.

Competing interests: The authors declare that they have no competing interests.

\section{Author Details}

${ }^{1}$ Health Promotion Division, Ghana Health Service, Accra, Ghana.

${ }^{2}$ Department of Population and Health, University of Cape Coast, Cape Coast, Ghana.

${ }^{2}$ Department of Population and Health, University of Cape Coast, Cape Coast, Ghana. 


\section{References}

1. Mascarenhas MN, Flaxman SR, Boerma T, Vanderpoel S, Stevens GA. National, regional, and global trends in infertility prevalence since 1990: a systematic analysis of 277 health surveys. PLoS Med. 2012; 9: 1-12:e1001356. doi: 10.1371/journal.pmed.1001356

2. Hollos $M$, Whitehouse B. Women in limbo: Life course consequences of infertility in a Nigerian community. Human Fertility Cambridge, 2014;17:188-191.

http://dx.doi.org/10.3109/14647273.2014. 936052

3. Asemota OA, Klatsky P. Access to infertility care in the developing world: the family promotion gap. Semin Reprod Med. 2015 Jan;33(1):17-22. doi: 10.1055/s-0034-1395274. Epub 2015 Jan 7. PMID: 25565507.

4. Geelhoed DW, Nayembil D, Asare K, Schagen Van Leeuwen JH, Roosmalin J. Infertility in rural Ghana. International Journal of Gynaecology and Obstetrics 2002;79: 137-142. [PubMed] [Google Scholar]

5. Mabasa L F.The psychological impact of infertility on the African women and their families. Unpublished Doctoral thesis. University of South Africa, Pretoria;2002

6. Washija NR, Pool R. Traditional healers, STDs and infertility in Northwest Tanzania. In: Boerma, J. T, Mgalla, Z. (eds). Women and Infertility in Sub-Saharan Africa: A Multi-Disciplinary Perspective. Amsterdam, NL: KIT Publishers; 2001

7. Harms R. Infertility: Causes. 2011.Retrieved from: http://www.May oclinic.com/health/ infertility/DS00310/DSECTION=causes.

8. Petraglia F, Serour GI, Chapron C. The changing prevalence of infertility. Int J Gynaecol Obstet. 2013 Dec;123 Suppl 2:S4-8. doi: 10.1016/j.ijgo.2013.09.005. Epub 2013 Sep 7. PMID: 24112745.

9. Joffe M.What has happened to human fertility? Hum Reprod. 2010; 25(2): 295 CrossRefView Record in Scopus Google Scholar

10. Nahar P. Misery of empty laps: Life of childless women in Bangladesh. FV \& V in ObGyn 2012; 28-34. DOI: $10.3109 / 14647273.2012 .658111$

11. Nahar P, Richters A. Suffering of childless women in Bangladesh: the intersection of social identities of gender and class. Anthropol Med. 2011 Dec;18(3):327-38. doi: 10.1080/13648470.2011.615911. PMID: 22060126.

12. Fledderjohann, JJ . 'Zero is not good for me': Implications of infertility in Ghana. Human Reproduction 2012; 27: 1383-90 Google Scholar | Crossref | Medline | ISI

13. Gerrits T. Social and cultural aspects of infertility in Mozambique. Patient Education and Counselling. 1997;31:39-48.

14. Onah N. The sociocultural perception and implications of childlessness in Anambra State. In Kisekka, M. N. (ed) Women's Health Issues in Nigeria. Nigeria: Tamza Publishing Company Limited.1992; 77-82.

15. Goody J. The Social Organisation of the Lo Wiili. London: Oxford University Press. 1956 
16. Astuti R.Cattle beget children\|-but women must bear them: Fertility, sterility and belonging among women in Swaziland. In Tielman, H.J. (ed) Scenes of change: Visions on Developments in Swaziland. Papers presented at the seminar on Social sciences in Swaziland '. Free University Amsterdam. 1988;191-201.

17. Caldwell JC, Caldwell P. Cultural forces tending to sustain high fertility. In Ascadi G, Johnson-Ascardi G, Bulutao R. (eds.) Population Growth and Reproduction in Sub-Saharan Africa: Technical Analysis of Fertility and its consequences. Washington D.C.: The World Bank. 1990;199-214.

18. Nahar P, Sharma A, Sabin K, Begum L, Ahsan S K, Baqui AH. Living with infertility: Experiences from urban slum populations in Bangladesh. Reproductive Health Matters. 2000; 8 (15): 33-44.

19. Bharadwaj A. Why adoption is not an option in India: the visibility of infertility, the secrecy of donor insemination, and other cultural complexities. Soc Sci Med. 2003 May;56(9):1867-80. doi:

10.1016/s0277-9536(02)00210-1. PMID: 12650726

20. Bardaweel SK, Shehadeh M, Suaifan GA, Kilani MV. Complementary and alternative medicine utilization by a sample of infertile couples in Jordan for infertility treatment: clinics-based survey. BMC Complement Altern Med. 2013 Feb 16;13:35. doi: 10.1186/1472-6882-13-35. PMID: 23414246; PMCID: PMC3599001.

21. Burns LH, Covington SN. Psychology of infertility. In S. N. Covington, L.H. Burns, S. N. Covington, \& L. H. Burns (Eds.), Infertility counselling: A comprehensive handbook for clinicians (2nd ed., pp. 1-19). New York, NY: Cambridge University Press,2006

22. Zegers-Hochschild F, Adamson GD, de Mouzon J, Ishihara O, Mansour R, Nygren RK, Sullivan E, van der Poel S, on behalf of ICMART and WHO, The International Committee for Monitoring Assisted Reproductive Technology (ICMART) and the World Health Organization (WHO) Revised Glossary on ART Terminology, 2009, Human Reproduction, Volume 24, Issue 11, November 2009, Pages 26832687, https://doi.org/10.1093/humrep/dep343

23. European Society of Human Reproduction and Embryology (ESHRE). ART Fact Sheet. 2012. http://www.eshre.eu/ESHRE/English/Guidelines-Legal/ART-fact-sheet/page.aspx/1061

24. Jones HW, Cooke I, Kempers R, Brinsden P, Saunders D. International Federation of Fertility Societies: Surveillance 2010.

25. Gerrits T. Assisted reproductive technologies in Ghana: transnational undertakings, local practices and 'more affordable' IVF. Reprod Biomed Soc Online. 2016 Jun 21;2:32-38. doi:

10.1016/j.rbms.2016.05.002. PMID: 29892714; PMCID: PMC5991875.

26. Chimbatata NBW, Malimba C. Infertility in sub-Saharan Africa: A woman's issue for how long? A qualitative review of literature. Open Journal of Social Sciences, 2016;4: 96-102. s. http://www.scirp.org/journal/jss http://dx.doi.org/10.4236/jss.2016.48012

27. Andersen R. A Behavioural Model of families' use of health services. Research Series No. 25. Chicago, IL: Center for Health Administration Studies, University of Chicago, 1968.

28. Andersen R, Newman JF. Societal and individual determinants of medical care utilization in the United States. Milbank Mem Fund Q Health Soc. 1973; 51(1):95124 doi: 10. 2307/3349613. 
Available from: http://dx.doi.org/10.2307/3349613.

29. Andersen RM, Davidson, PL. Improving access to care in America: Individual and contextual indicators. In changing the U.S. health care system: Key issues in health services, policy and management, edited by R. Andersen, T. Rice, and J. Kominski, 3-30. San Francisco: Jossey-Bass, 2001

30. Andersen R. Revisiting the Behavioural Model and access to medical care: Does it matter? Journal of Health and Social Behaviour, 1995;36(1): 1-10. 1-10. doi:10.2307/2137284

31. Horbst V. Male perspectives on infertility and Assisted Reproductive Technologies in Sub-Saharan Contexts. Facts, Views \& Vision in ObGyn Monograph, 2010; 8:22-27.

32. Mechanic D. Medical Sociology: A comprehensive text (2nd ed.). New York, NY: Free Press, 1978.

33. Pescosolido BA. Illness careers and network ties: A conceptual model of utilization and compliance. In G. Albrecht, \& J. Levy (Eds.), Advances in medical sociology (pp. 161-184). Greenwich, CT: JAl Press, 1991.

34. Chambers GM, Sullivan EA, Ishihara O, Chapman MG, Adamson GD. The economic impact of assisted reproductive technology: a review of selected developed countries. Fertil Steril. 2009 Jun;91(6):2281-94. doi: 10.1016/j.fertnstert.2009.04.029. PMID: 19481642.

35. Huddleston HG, Cedars MI, Sohn SH, Giudice LC, Fujimoto VY. Racial and ethnic disparities in reproductive endocrinology and infertility. Am J Obstet Gynecol. 2010 May;202(5):413-9. doi: 10.1016/j.ajog.2009.12.020. Epub 2010 Mar 6. PMID: 20207341.

36. Dyer SJ, Patel M. The economic impact of infertility on women in developing countries - a systematic review. Facts Views Vis Obgyn. 2012;4(2):102-9. PMID: 24753897; PMCID: PMC3987499.

37. Donkor ES, Sandall J. (2007). The impact of perceived stigma and mediating social factors on infertility-related stress among women seeking infertility treatment in Southern Ghana. Soc Sci Med. 2007;65: 1683-94. doi: 10.1016/j.socscimed.2007.06.003. Epub 2007 Jul 27.

38. Moragianni VA, Penzias AS.Cumulative live-birth rates after assisted reproductive technology.Curr. Opin. Obstet. Gynecol, 2010; 22: 189-192. View Record in ScopusGoogle Scholar

39. Volgsten H, Ekselius L, Poromaa IS Svanberg AS. (2010). Personality traits associated with depressive and anxiety disorders in infertile women and men undergoing in vitro fertilization treatment. Acta Obstetricia Gynecologica, 2010; 89:27-

\section{4. https://doi.org/10.3109/00016340903447396}

40. McLernon DJ, Harrild K, Bergh C, Davies MJ, de Neubourg D, Dumoulin JC, Gerris J, Kremer JA, Martikainen H, Mol BW, Norman RJ, Thurin-Kjellberg A, Tiitinen A, van Montfoort AP, van Peperstraten $A M$, Van Royen E, Bhattacharya S. Clinical effectiveness of elective single versus double embryo transfer: meta-analysis of individual patient data from randomised trials. BMJ. $2010 \mathrm{Dec}$ 21;341:c6945. doi: 10.1136/bmj.c6945. PMID: 21177530; PMCID: PMC3006495.

41. Courbiere B, Oborski V, Braunstein D, Desparoir A, Noizet A, Gamerre M. Obstetric outcome of women with in vitro fertilization pregnancies hospitalized for ovarian hyperstimulation syndrome: A case- 
control study. Fertil Steril. 2011 Apr;95(5):1629-32. doi: 10.1016/j.fertnstert.2010.12.015. Epub 2011 Jan 8. PMID: 21215968. 